\title{
Isolated subpopulations of mass-harvested pig oocytes and their characterization by size, incidence of atresia and competence to mature in culture
}

\author{
S. T. Homa, R. W. McGaughey and C. Racowsky \\ Department of Zoology, Arizona State University, Tempe, Arizona 85287, U.S.A.
}

\begin{abstract}
Summary. Pig oocytes were hand collected after follicular puncture or were mass harvested with stainless-steel screens and purified on sucrose density gradients. Most oocytes obtained by mass harvesting with a $75 \mu \mathrm{m}$ screen and selecting on a 0 and $30 \%$ discontinuous sucrose gradient were meiotically incompetent and atretic after culture. Two enriched populations of oocytes were isolated from the $0-15 \%$ and $15-30 \%$ interfaces with a $106 \mu \mathrm{m}$ screen and a $0 \%, 15 \%$ and 30\% 2-step discontinuous sucrose gradient. These oocyte populations differed significantly in size $(P<0.001, t$ test $)$ and in meiotic competence. More than $50 \%$ of the larger oocytes matured compared with $14 \%$ of the smaller oocytes $(P<0.002)$. Of the larger oocytes, $21 \%$ progressed beyond meiotic metaphase $I$, whereas all of the maturing small oocytes were arrested at first metaphase after culture $(P<0.002)$. Yields were 45 times greater for oocytes mass harvested with a $106 \mu \mathrm{m}$ screen and a $15 \%$ sucrose density gradient than for oocytes hand collected in the same period of time. Layering these mass-harvested oocytes over a second $15 \%$ sucrose gradient or hand sorting the mass-harvested oocytes after culture increased the proportion of maturing oocytes compared with oocytes which were mass harvested before culture and produced higher proportions of oocytes at telophase I or beyond $(P<0.002)$. The results demonstrate that mass harvesting of pig oocytes is more efficient than hand selection, and that oocytes collected and selected in this way are at least as capable of meiotic maturation as are oocytes hand selected before culture.
\end{abstract}

Keywords: oocytes; meiosis; maturation; size; atresia; subpopulations

\section{Introduction}

It is well established that mammalian oocytes, when removed from their follicular environment, will resume meiosis spontaneously and complete maturation in culture (for reviews, see Tsafriri, 1978; Masui \& Clarke, 1979; Channing et al., 1980). However, many oocytes in mammalian ovaries are atretic (Himeistein-Braw et al., 1976; Byskov, 1978; McGaughey et al., 1979) and most non-atretic oocytes are small and incapable of maturation in culture (Tsafriri \& Channing, 1975; Tsafriri, 1978; McGaughey et al., 1979; Channing et al., 1980). Studies of mammalian oocyte development have been restricted by the limited numbers of oocytes obtained by hand collection after puncture of individual follicles, but Dunbar $e t$ al. (1978) developed a procedure for mass harvesting large numbers of pig oocytes, thus permitting large-scale biochemical analyses of these cells (Homa et al., 1986).

Although the previously applied mass-harvesting procedure provides sufficient numbers of oocytes for biochemical analyses (Dunbar et al., 1978; Homa et al., 1986), the procedure yields populations of oocytes heterogeneous in size and probably in developmental competence. We have now further modified the mass-harvesting procedure to provide relatively homogeneous populations of oocytes. 


\section{Materials and Methods}

Collection of oocytes. Pig reproductive tracts were obtained from prepubertal females from Arizona Pork Products Inc. (Phoenix, AZ). Procedures for oocyte collection involved removal by puncturing individual follicles (Procedure 1, hand collection) or modifications of a mass-harvesting technique (Procedures 2-4).

Procedure 1. Medium-sized antral follicles (3-5 $\mathrm{mm}$ diameter) were punctured with sterile 18-gauge needles as previously described (Rice \& McGaughey, 1981) and, with the use of a dissecting microscope, the liberated oocytes were collected in chemically defined culture medium, 2A-BMOC (McGaughey, 1977), by means of mouth-operated pipettes. Comparatively large oocytes with adherent cumulus masses, previously described as " $\mathrm{A}$ " oocytes (McGaughey et al., 1979), were selected for culture. Cumulus cells were mechanically removed from selected oocytes by using small-bore pipettes (Hillensjö et al., 1975).

Procedure 2. Collection of a heterogeneous population of oocytes was accomplished by using the mass-harvesting procedure described by Homa $\mathrm{et}$ al. (1986). Only follicles of $<5 \mathrm{~mm}$ in diameter were used. The oocytes were harvested in $0.87 \%(\mathrm{w} / \mathrm{v}) \mathrm{NaCl}+2.5 \mathrm{~mm}$-Hepes (Homa et al., 1986) containing $1 \mathrm{mm-EDTA}$ at $\mathrm{pH} 7.4$ on a stainlesssteel screen of $75 \mu \mathrm{m}$ pore size. The oocytes were denuded of adherent cumulus cells by vortexing for $30 \mathrm{sec}$ in $1 \%$ $(\mathrm{w} / \mathrm{v})$ sodium citrate in $10 \mathrm{~mm}$-EDTA ( $\mathrm{pH} 7.4)$, and then resuspended in $0.87 \%(\mathrm{w} / \mathrm{v}) \mathrm{NaCl}+2.5 \mathrm{mM}-\mathrm{Hepes}(\mathrm{pH} 7.4)$ containing $1 \mathrm{~mm}$-EDTA. The cell suspension was layered over $30 \%(\mathrm{w} / \mathrm{v})$ sucrose in Medium 2A-BMOC. After centrifuging at $1400 \mathrm{~g}$ for $4 \mathrm{~min}$, the purified oocytes were removed from the $0-30 \%$ sucrose interface and washed 3 times in Medium 2A-BMOC containing $0.5 \%(\mathrm{w} / \mathrm{v})$ bovine serum albumin.

Procedure 3. Oocytes were mass harvested as described in Procedure 2 except that Medium 2A-BMOC was substituted for $0.87 \%(\mathrm{w} / \mathrm{v}) \mathrm{NaCl}+2.5 \mathrm{~mm}$-Hepes containing $1 \mathrm{mM}$-EDTA, and oocytes were collected on a $106 \mu \mathrm{m}$ screen. Cumulus cells were removed by vortexing for $30 \mathrm{sec}$ in $1 \%(\mathrm{w} / \mathrm{v})$ sodium citrate in $10 \mathrm{mM}-\mathrm{EDTA}, \mathrm{pH} 7 \cdot 4$. The cell suspension was passed through a $106 \mu \mathrm{m}$ screen and the oocytes were collected from the screen surface in Medium $2 \mathrm{~A}-\mathrm{BMOC}$. This suspension was layered over a $15 \%$ and $30 \%$ discontinuous sucrose gradient to determine whether the oocytes could be separated into different subpopulations. After centrifuging at $1400 \mathrm{~g}$ for $4 \mathrm{~min}$, purified groups of oocytes were collected separately from the $0-15 \%$ and from the $15-30 \%$ sucrose interfaces and washed 3 times in Medium 2A-BMOC containing $0.5 \%$ bovine serum albumin.

Procedure 4. Oocytes were harvested as in Procedure 3. Purified oocytes were obtained from the interface of a onestep $0 \%, 15 \%$ sucrose gradient after centrifugation (as described above), and washed 3 times in Medium 2A-BMOC containing $0.5 \%$ bovine serum albumin.

Culture conditions. Oocytes, hand selected by individual follicular puncture (Procedure 1), were incubated overnight in wells of sterile Lab-Tek tissue culture chamber slides (No. 4838, Miles Scientific, IL), with 6-12 cells $/ 0.2 \mathrm{ml}$ medium, at $37^{\circ} \mathrm{C}$ in an humidified atmosphere of $5 \% \mathrm{CO}_{2}$ in air. Oocytes, mass harvested by using Procedures $2-4$, were incubated overnight in sterile Erlenmeyer flasks $\left(4-8 \times 10^{3}\right.$ cells $/ \mathrm{ml}$ medium) or in $35 \mathrm{~mm} \times 10 \mathrm{~mm}$ sterile Falcon Petri dishes (Becton Dickinson Labware, CA $\left(1.0 \times 10^{3} \mathrm{cells} / \mathrm{ml}\right.$ medium) under the same conditions. In all cases the culture medium was $2 \mathrm{~A}-\mathrm{BMOC}$ containing $0.5 \%(\mathrm{w} / \mathrm{v})$ bovine serum albumin. For Procedure 4 , the purified oocytes were cultured overnight and then split into 3 groups. The first group was prepared immediately for examination of meiotic stage (Method A, see below). The second group (Method B) was selected visually under the light microscope by removing degenerate oocytes with mouth-operated pipettes after incubation, and then scored for maturation. The third group (Method C) was centrifuged over 15\% sucrose in Medium 2A-BMOC, as in Procedure 4, after incubation: oocytes recovered from the 0-15\% sucrose interface were washed and scored for maturation.

Determination of meiotic stage. Oocytes were placed in sodium citrate as previously described (McGaughey \& Polge, 1971), fixed, and air dried and stained with Wrights's stain (Rice \& McGaughey, 1981). For each experiment, all the hand-collected oocytes (Procedure 1) were mounted on 3-6 slides (6-12 oocytes per slide), whereas massharvested oocytes (Procedures 2 and 3) were selected at random and mounted on 12 slides with 8-12 oocytes per slide. When oocytes were mass harvested by Procedure 4, 3 slides were prepared with 8-12 oocytes per slide for each experiment. Oocyte maturation was scored cytogenetically. The chromatin of germinal vesicle-stage oocytes was classified as normal (fibrous or diffuse), or degenerate as defined by McGaughey et al. (1979). Maturing oocytes were classified as those which had progressed to or beyond diakinesis-metaphase I, and as normal or degenerate (McGaughey et al., 1979). Statistical analyses were carried out using Student's $t$ test.

\section{Results}

Initial experiments, using Procedure 2, demonstrated that most mass-harvested pig oocytes collected on a $75 \mu \mathrm{m}$ screen and purified on a single step $30 \%$ sucrose density gradient (Homa et al., 1986) did not resume meiosis during culture and were mostly degenerate (Table 1). Of those oocytes that matured, the majority did not develop beyond first meiotic metaphase and half of these maturing oocytes were degenerate. 
Table 1. Spontaneous maturation of pig oocytes mass harvested by Procedure 2

\begin{tabular}{lcccc}
\hline & & \multicolumn{3}{c}{ Examined oocytes (\%) } \\
\cline { 3 - 5 } Oocytes & Total & $\begin{array}{c}\text { Germinal } \\
\text { vesicle }\end{array}$ & $\begin{array}{c}\text { Diakinesis- } \\
\text { metaphase I }\end{array}$ & $\begin{array}{c}\text { Anaphase I- } \\
\text { metaphase II }\end{array}$ \\
\hline $\begin{array}{l}\text { Total } \\
\text { examined }\end{array}$ & 282 & $68.7 \pm 13.0$ & $21.8 \pm 5.6$ & $9.5 \pm 4 \cdot 2$ \\
$\begin{array}{l}\text { Degenerate } \\
\text { (as \% of total) }\end{array}$ & $70.0 \pm 7.2$ & $89.5 \pm 4.1$ & $48.2 \pm 10.2$ & $5.0 \pm 5.8$ \\
\hline
\end{tabular}

Values are mean \pm s.e.m. for 6 replicate experiments.

Table 2. Numbers of oocytes in two enriched subpopulations (by size) of pig oocytes measured with or without a zona pellucida obtained by Procedure 3

\begin{tabular}{lccc}
\hline \multirow{2}{*}{$\begin{array}{l}\text { Zona } \\
\text { pellucida }\end{array}$} & $\begin{array}{c}\text { Oocyte } \\
\text { diam. }(\mu \mathrm{m})\end{array}$ & $0-15 \%$ & $15-30 \%$ \\
\cline { 3 - 4 } Present & $<110$ & 0 & 1 \\
& $110-119$ & 0 & 2 \\
& $120-129$ & 0 & 8 \\
Mean \pm s.e.m. & $130-139$ & 10 & 0 \\
\hline Absent & $140-149$ & 2 & 0 \\
& & $134 \cdot 3 \pm 1 \cdot 2$ & $119 \cdot 4 \pm 3 \cdot 0^{*}$ \\
& $>75$ & 0 & 1 \\
& $75-84$ & 0 & 4 \\
Mean \pm s.e.m. & $95-94$ & 1 & 4 \\
\hline *P & $105-114$ & 4 & 2 \\
& $>114$ & 3 & 0 \\
& & $106 \cdot 1 \pm 2 \cdot 7$ & $87 \cdot 7 \pm 2 \cdot 8 *$ \\
\hline
\end{tabular}

To reduce the number of small and atretic oocytes in the mass-harvesting procedure, Procedure 3 was adopted. Table 2 shows that two enriched populations of oocytes, which differ significantly in average diameter $(P<0.001)$, could be separated on this two-step sucrose gradient, the larger oocytes having a lower density than the smaller oocytes. These oocyte populations also were distinguished by meiotic competence (Table 3 ). A significantly higher proportion $(P<0.002)$ of the smaller oocytes remained immature compared with the larger oocytes after culture (Table 3 ). Moreover, about one fifth of the larger oocytes progressed to telophase I or beyond during $24 \mathrm{~h}$ of culture, whereas none of the smaller maturing oocytes progressed beyond first meiotic metaphase. Procedure 3 also reduced the proportion of degenerate oocytes after culture as compared with Procedure 2 (Table 1). This decrease in total degenerate oocytes was attributed to the removal of degenerate immature oocytes by Procedure 3 because the proportion of degenerate mature oocytes did not change compared with that in Procedure 2. The incidence of degenerate oocytes collected at the $0-15 \%$ sucrose interface was not significantly different from that of oocytes collected at the $15-30 \%$ sucrose interface (Table 3), although both values were lower than that of degenerate oocytes obtained with Procedure 2.

When a one-step sucrose density gradient consisting of $15 \%$ sucrose alone was used for collecting a population of large meiotically competent oocytes (Procedure 4), comparisons were made with 
Table 3. Maturation in two subpopulations of pig oocytes obtained by Procedure 3

\begin{tabular}{lccccc}
\hline & & & \multicolumn{2}{c}{ Mean \pm s.e.m. of examined oocytes (\%) } \\
\cline { 5 - 6 } Interface & Oocytes & Total & $\begin{array}{c}\text { Germinal } \\
\text { vesicle }\end{array}$ & $\begin{array}{c}\text { Diakinesis- } \\
\text { metaphase I }\end{array}$ & $\begin{array}{c}\text { Anaphase I- } \\
\text { metaphase II }\end{array}$ \\
\hline $\begin{array}{l}0-15 \% \\
(7 \text { replicates })\end{array}$ & $\begin{array}{c}\text { Total } \\
\text { examined } \\
\text { Degenerate } \\
(\% \text { of total) }\end{array}$ & $36 \cdot 2 \pm 9 \cdot 1$ & $30 \cdot 7 \pm 9 \cdot 0$ & $17 \cdot 6 \pm 9 \cdot 5$ & $5 \cdot 6 \pm 6 \cdot 1$ \\
\hline $\begin{array}{l}15-30 \% \\
(6 \text { replicates })\end{array}$ & $\begin{array}{c}\text { Total } \\
\text { examined } \\
\text { Degenerate } \\
(\% \text { of total) }\end{array}$ & $47 \cdot 6 \pm 12$ & $46 \cdot 6 \pm 13$ & $10 \cdot 0 \pm 11$ & $21 \cdot 4 \pm 5 \cdot 2^{* *}$ \\
\hline
\end{tabular}

${ }^{*} P<0.05 ;{ }^{* *} P<0.002$ for oocytes within the same meiotic stage.

Table 4. Yields of oocytes by hand-collection or mass-harvesting procedures

\begin{tabular}{lcc}
\hline & $\begin{array}{c}\text { Hand collection } \\
\text { (Procedure 1) }\end{array}$ & $\begin{array}{c}\text { Mass harvesting } \\
\text { (Procedure 4) }\end{array}$ \\
\hline Ovaries per collection & $7 \cdot 3(6-8)$ & $53 \cdot 7(40-78)$ \\
Oocytes per collection & $41 \cdot 0(25-60)$ & $1766 \cdot 7(900-3100)$ \\
Oocytes per ovary & $5 \cdot 5(4 \cdot 2-7 \cdot 5)$ & $30 \cdot 8(22 \cdot 5-39 \cdot 7)$ \\
\hline
\end{tabular}

Values represent means of 3 collections, with ranges in parentheses.

Table 5. Analysis of maturation and atresia of pig oocytes in culture after hand collection (Procedure 1) or mass harvesting (Procedure 4)

\begin{tabular}{|c|c|c|c|c|c|c|c|}
\hline \multirow[b]{2}{*}{$\begin{array}{l}\text { Selection } \\
\text { method }\end{array}$} & \multirow{2}{*}{$\begin{array}{l}\text { No. of } \\
\text { oocytes } \\
\text { examined } \\
\text { (no. of } \\
\text { replicates) }\end{array}$} & \multirow{2}{*}{$\begin{array}{l}\text { Mean no. of } \\
\text { oocytes } \\
\text { collected/ } \\
\text { replicate }\end{array}$} & \multicolumn{5}{|c|}{$\begin{array}{c}\% \text { of total oocytes } \\
\text { (\% degenerate for each stage) }\end{array}$} \\
\hline & & & GV & Mature & $\begin{array}{l}\text { Diakinesis- } \\
\text { metaphase I }\end{array}$ & $\begin{array}{l}\text { Anaphase I- } \\
\text { metaphase II }\end{array}$ & Degenerate \\
\hline Procedure 1 & $165(6)$ & $33 \pm 6$ & $\begin{array}{c}28 \cdot 8 \pm 4 \cdot 7^{\mathrm{a}} \\
(35 \cdot 4 \pm 10 \cdot 3)\end{array}$ & $\begin{array}{l}71 \cdot 2 \pm 5 \cdot 1^{\mathrm{a}} \\
(1 \cdot 5 \pm 1 \cdot 7)\end{array}$ & $\begin{array}{l}17 \cdot 0 \pm 3 \cdot 5^{a, b} \\
(5 \cdot 5 \pm 5 \cdot 5)\end{array}$ & $54 \cdot 2 \pm 7 \cdot 8^{\mathrm{a}}$ & $\begin{array}{c}9 \cdot 5 \pm 1 \cdot 4^{\mathrm{a}} \\
-\end{array}$ \\
\hline $\begin{array}{l}\text { Procedure } 4 \\
\text { Method A }\end{array}$ & $926(6)$ & $1747 \pm 336$ & $\begin{array}{l}47 \cdot 1 \pm 4 \cdot 0^{b} \\
(54 \cdot 3 \pm 4 \cdot 6)\end{array}$ & $\begin{array}{l}52 \cdot 9 \pm 4 \cdot 3^{b} \\
(3 \cdot 2 \pm 1 \cdot 3)\end{array}$ & $\begin{array}{l}23 \cdot 9 \pm 3 \cdot 5^{b \cdot c} \\
(6 \cdot 5 \pm 2 \cdot 7)\end{array}$ & $\begin{array}{l}29.0 \pm 3.9^{b} \\
(0.8 \pm 0.6)\end{array}$ & $28 \cdot 0 \pm 3 \cdot 5^{b}$ \\
\hline Method B & $114(3)$ & $507 \pm 68$ & $\begin{array}{c}7 \cdot 5 \pm 2 \cdot 5^{c} \\
(35 \cdot 7 \pm 18 \cdot 0)\end{array}$ & $\frac{92 \cdot 5 \pm 3 \cdot 0^{c}}{(0)}$ & $31 \cdot 1 \pm 1 \cdot 6^{c}$ & $61 \cdot 3 \pm 3 \cdot 5^{a}$ & $3 \cdot 4 \pm 2 \cdot 0^{c}$ \\
\hline Method C & $91(3)$ & $599 \pm 68$ & $\begin{array}{l}30 \cdot 7 \pm 3 \cdot 9^{a} \\
(53 \cdot 1 \pm 22 \cdot 5)\end{array}$ & $\begin{array}{l}69 \cdot 2 \pm 4 \cdot 8^{a} \\
(1 \cdot 8 \pm 2 \cdot 2)\end{array}$ & $\begin{array}{l}9 \cdot 9 \pm 0 \cdot 1^{\mathrm{a}} \\
(0)\end{array}$ & $\begin{array}{l}59 \cdot 3 \pm 3 \cdot 9^{\mathrm{a}} \\
(2 \cdot 1 \pm 2 \cdot 1)\end{array}$ & $\begin{array}{c}16 \cdot 6 \pm 7 \cdot 0^{\mathrm{a}, \mathrm{b}} \\
-\end{array}$ \\
\hline
\end{tabular}

Values are mean \pm s.e.m. Values with different superscript letters are significantly different within the same meiotic stage $(P<0.05$ at least $)$.

populations of control oocytes collected by Procedure 1. Mass harvesting (Procedure 4) yielded 45 times more oocytes than did hand collection by Procedure 1 (Table 4). Moreover, 7-8 times more ovaries were processed with the mass-harvesting procedures compared with hand collection during equivalent collection periods (i.e. $2 \cdot 5 \mathrm{~h}$ ).

The incidences of maturation beyond the germinal vesicle stage differed significantly $(P<0.05)$ for oocytes collected by Procedures 1 and 4 (Method A) with a significantly higher proportion 
$(P<0.05)$ of hand-collected oocytes progressing beyond metaphase I (Table 5). There was also a significantly lower overall proportion $(P<0.001)$ of degenerate oocytes in the hand-collected population than in the mass-harvested population of oocytes (Method A in Table 5). Selection by Method $C$ produced a population of oocytes in which the incidence of maturation did not differ significantly from that of oocytes collected by Procedure 1. However, selection of mass-harvested oocytes by Method B gave a mean incidence of maturation that was significantly higher $(P<0.05)$ than that of oocytes collected by Procedure 1. Moreover, none of the maturing oocytes collected by Method B were degenerate. The proportion of maturing oocytes which progressed through the first meiotic division to telophase I or metaphase II was also enhanced by Methods B and C of Procedure 4 ( $P<0.002$ for both), to a value comparable to that of oocytes collected by Procedure 1 . Although selection by Methods $B$ and $C$ reduced the yield of oocytes by about one-third compared with Method A, Methods B and C yielded a nearly 17-fold increase in mean number of oocytes compared with Procedure 1 (Table 5).

\section{Discussion}

In the present study, the previously published mass-harvesting procedure (Homa et al., 1986) has been modified to allow selection of enriched populations of oocytes according to size, atresia and the ability to mature during culture (see Procedures 3 and 4). By using a larger screen size (106 $\mu \mathrm{m})$, the smallest oocytes can be eliminated and the proportion of atretic oocytes effectively reduced. The remainder can be subjected to a discontinuous sucrose density gradient, permitting the separation of a population of large meiotically competent oocytes (0-15\% sucrose interface) from a group of smaller developmentally immature oocytes (15-30\% sucrose interface) which are incapable of completing meiotic maturation. The larger oocytes may be further selected to increase the proportion of cells beyond metaphase I after culture. These results support earlier findings that larger oocytes have a greater capacity for spontaneous meiotic maturation than smaller oocytes (Tsafriri \& Channing, 1975; Tsafriri, 1978; McGaughey et al., 1979; Channing et al., 1980).

The results demonstrate that the use of a larger screen size $(106 \mu \mathrm{m})$ and Medium 2A-BMOC for harvesting oocytes as described in Procedures 3 and 4 yields a lower incidence of atretic cells compared with Procedure 2 in which EDTA was included in the collection medium. Although most oocytes in the ovary are atretic (Himelstein-Braw et al., 1976; Byskov, 1978; McGaughey et al., 1979), it could be argued that temporary removal of divalent cations in the presence of EDTA during harvesting with Procedure 2 decreased oocyte survival, because it has been reported that calcium has considerable influence on mammalian oocyte viability (De Felici \& Siracusa, 1982; Maruska et al., 1984) and meiotic maturation (Paleos \& Powers, 1981; De Felici \& Siracusa, 1982; Jagiello et al., 1982; Maruska et al., 1984; Racowsky, 1986) in culture. However, other investigations revealed that the effects of collecting and incubating pig oocytes in calcium-free medium were reversible after $3 \mathrm{~h}$ (Bae \& Channing, 1985). In the present study, pig oocytes mass harvested in the presence of EDTA for $2.5 \mathrm{~h}$ (Procedure 2) were subsequently cultured overnight in medium containing $1.7 \mathrm{mM}-\mathrm{CaCl}_{2}$. Although about $30 \%$ of the oocytes obtained with Procedure 2 matured (Table 1), the majority of these oocytes did not progress beyond first meiotic metaphase, and about one-half of them exhibited signs of degeneration. This is probably due to the small size of these oocytes, which are known to exhibit reduced competence for meiotic maturation (Tsafriri \& Channing, 1975; Tsafriri, 1978; McGaughey et al., 1979; Channing et al., 1980) and which are relatively insensitive to calcium deficiency (De Felici \& Siracusa, 1982). Moreover, brief exposure of oocytes to EDTA using Procedures 3 and 4 did not appear to affect meiotic competence as more than $50 \%$ of the oocytes matured in culture and a large proportion of maturing oocytes progressed beyond meiotic metaphase I.

It was shown previously that mass harvesting yields 200-300 oocytes per ovary using nylon mesh screens (Dunbar et al., 1978) or using a $75 \mu \mathrm{m}$ stainless-steel screen (Homa et al., 1986) as in Procedure 2. By selecting for size and ability to mature in culture using a larger screen size (106 $\mu \mathrm{m})$ 
and a $0 \%$ and $15 \%$ discontinuous sucrose gradient as in Procedure 4 , the yield of mass-harvested oocytes was reduced to $10 \%$ (22-40 oocytes per ovary) of the previously reported yield. This observation again confirms previous findings that the majority of oocytes in the mammalian ovary are derived from small follicles and are meiotically incompetent or atretic (Tsafriri \& Channing, 1975; Bae \& Channing, 1985). Although selection after culture further reduces the mass-harvest yield, almost 20 times as many oocytes can be obtained using these procedures as by routine hand collection (Procedure 1) and more ovaries can be processed in the same period of time. It therefore appears that mass-harvesting procedures can be used efficiently to obtain large yields of mammalian oocytes.

The ability to separate oocytes on a large scale according to atresia, size and competence to mature in culture should greatly facilitate comparative studies during oocyte atresia and at different developmental stages, permitting a broader understanding of the physiological and biochemical processes involved in oocyte growth, development and maturation.

We thank Douglas Swank for excellent technical assistance and the Lalor Foundation for supporting this study.

\section{References}

Bae, I.H. \& Channing, C.P. (1985) Effect of calcium ion on the maturation of cumulus-enclosed pig follicular oocytes isolated from medium-sized graafian follicles. Biol. Reprod. 33, 79-87.

Byskov, A.G. (1978) Follicular atresia. In The Vertebrate Ovary. pp. 533-562. Ed. R. E. Jones. Plenum Press, New York.

Channing, C.P., Schaerf, F.W., Anderson, L.D. \& Tsafriri, A. (1980) Ovarian follicular and luteal physiology. Int. Rev. Physiol. 22, 117-201.

De Felici, M. \& Siracusa, G. (1982) Survival of isolated, fully grown mouse ovarian oocytes is strictly dependent on external $\mathrm{Ca}^{2+}$. Devl Biol. 92, 539-543.

Dunbar, B.S., Wardrip, N.J. \& Hedrick, J.L. (1978) Isolation and physicochemical properties of porcine zona pellucida. J. Cell Biol. 79, 163a, Abstr.

Hillensjö, T., Hamberger, L. \& Ahrén, K. (1975) Respiratory activity of oocytes isolated from ovarian follicies of the rat. Acta endocr., Copenh. 78, 751-759.

Himelstein-Braw, R., Byskov, A.G., Peters, H. \& Faber, M. (1976) Follicular atresia in the infant human ovary. J. Reprod. Fert. 46, 55-59.

Homa, S.T., Racowsky, C. \& McGaughey, R.W. (1986) Lipid analysis of immature pig oocytes. J. Reprod. Fert. 77, 425-434.

Jagiello, G., Ducayen, M.B., Downey, R. \& Jonassen, A. (1982) Alterations of mammalian oocyte meiosis I with divalent cations and calmodulin. Cell Calcium 3, 153-162.

Maruska, D.V., Leibfried, M.L. \& First, N.L. (1984) Role of calcium and the calcium-calmodulin complex in the resumption of meiosis, cumulus expansion, viability and hyaluronidase sensitivity of bovine cumulus-oocyte complexes. Biol. Reprod. 31, 1-6.
Masui, Y. \& Clarke, H.J. (1979) Oocyte maturation. Int. Rev. Cytol. 57, 185-281.

McGaughey, R.W. (1977) The maturation of porcine oocytes in minimal defined culture media with varied macromolecular supplements and varied osmolarity. Expl Cell Res. 109, 25-30.

McGaughey, R.W. \& Polge, C. (1971) Cytogenetic analysis of pig oocytes matured in vitro. J. exp. Zool. 176, 383-395.

McGaughey, R.W., Montgomery, D.H. \& Richter, J.D. (1979) Germinal vesicle configurations and patterns of polypeptide synthesis of porcine oocytes from antral follicles of different size, as related to their competency for spontaneous maturation. J. exp. Zool. 209, 239-254.

Paleos, G.A. \& Powers, R.D. (1981) The effect of calcium ion on the first meiotic division of the mammalian oocyte. J. exp. Zool. 217, 409-416.

Racowsky, C. (1986) The releasing action of calcium upon cyclic AMP-dependent meiotic arrest in hamster oocytes. J. exp. Zool. 239, 263-275.

Rice, C. \& McGaughey, R.W. (1981) Effect of testosterone and dibutyryl cAMP on the spontaneous maturation of pig oocytes. J. Reprod. Fert. 62, 245-256.

Tsafriri, A. (1978) Oocyte maturation in mammals. In The Vertebrate Ovary, pp. 409-442. Ed. R. E. Jones. Plenum Press, New York.

Tsafriri, A. \& Channing, C.P. (1975) Influence of follicular maturation and culture conditions on meiosis of pig oocytes in vitro. J. Reprod. Fert. 43, 149-152.

Received 12 March 1987 